\title{
LA MEMORIA INDÍGENA EN CAUTIVERIO FELIZ Y RAZÓN INDIVIDUAL DE LAS GUERRAS DILATADAS DEL REINO DE CHILE DE FRANCISCO NÚÑEZ DE PINEDA Y BASCUÑ̃́N
}

The Indian memory in Cautiverio feliz y razón individual de las guerras dilatadas del reino de Chile by Francisco Núñez de Pineda y Bascuñán

Sonia López Baena*

\section{Resumen}

Este trabajo tiene como propósito demostrar que la voz indígena presente en Cautiverio feliz y razón individual de las guerras dilatadas del reino de Chile no es una reivindicación de la alteridad sino un instrumento discursivo útil para la consecución del objetivo textual del cronista. Para ello, examinaremos las interferencias -voluntarias o involuntarias- de la voz del soldado Francisco Núñez de Pineda y Bascuñán en el trasvase lingüístico y cultural que hace en el registro letrado de la memoria araucana. Durante su cautiverio, el cronista tiene acceso a la oralidad que la configura y al modo en que se transmite entre los miembros del grupo. Irrumpirá en este proceso -como actor, durante su experiencia, y en su memorial, décadas más tarde- desde un imaginario criollo que, a pesar de haber madurado en la multicultural frontera araucana, conserva motivaciones de lucha de un pensamiento etnocéntrico.

Palabras clave: Memoria indígena. Oralidad. Escritura. Cautiverio. Imaginario criollo.

\section{Abstract}

The purpose of this paper is to show that the Indian voice included in Happy Captivity and Reason for the Prolonged Wars of the Kingdom of Chile is not a recognition of otherness, but a useful discursive instrument for achieving the chronicler's text objective. To that end, we examine the voluntary and involuntary interferences of the soldier's voice of Francisco Núñez de Pineda y Bascuñán within the written cultural and linguistic transfer from the Araucanian memory. During his captivity, the chronicler has access to its oral configuration and the way in which it is passed on to the members of the group. He interferes in this process -as an actor, during his experience, and as a memory writer a few decades later- and he always does it from a Creole imaginary that retains the fight motivations of ethnocentric thinking, despite having been shaped in the multicultural Araucanian frontier.

Key words: Indian memory. Orality. Writing. Captivity. Creole imaginary

Dentro de su investigación acerca de los cambios en la representación del "bárbaro" en las crónicas de cautiverios chilenos del siglo XVII, Gilberto Triviños marca una división entre los textos que muestran una "crucifixión (literal o simbólica) de los cautivos" - como los de Alonso de Ovalle, Juan Falcón o Alonso González de Nájera- y los que destacan por la narración de las "finezas bárbaras" (Concha, cit. en Triviños, Martirio) - como los de Diego de Rosales o de Francisco Núñez de Pineda y Bascuñán, de cuya obra vamos a tratar en este trabajo-. 
La propuesta crítica de Triviños sistematiza el paso de la brutalidad y de la combatividad indígena en Chile, que en el siglo XVI se desarrolla sobre la épica transmitida en los textos de Alonso de Ercilla o de José Acosta, a la docilidad que se les atribuye en el siglo XVII, idea que recupera el mensaje de la bula papal Sublimis deus (1537) y que evidencia la expansión del pensamiento del padre Bartolomé de Las Casas. En Chile, la Compañía de Jesús fue la promotora de la visión lascasiana del "buen salvaje", por la gran predisposición que encontró en los indios araucanos para ser evangelizados. Más tarde la orden, dirigida por el padre Luis de Valdivia, aprovecharía el argumento para promocionar la guerra defensiva en los años en los que la pugna por La Araucanía se había estancado en la frontera del río Biobío.

El cronista del siglo XVII conoce el manejo deficitario de la conquista de Chile y ya no puede ni quiere dar testimonio de la guerra como un conflicto heroico. Este panorama permite que los tipos infames (sin fama) asuman la voz del relato de lo acontecido dando a conocer sus episodios lamentables, lo que será una versión historiográfica alternativa a la oficial o lo que Triviños llama "el reverso del mito" de la conquista austral (La polilla, 72).

En esta línea, el soldado criollo Francisco Núñez de Pineda y Bascuñán construye Cautiverio feliz y razón individual de las guerras dilatadas del reino de Chile (1673) a partir de una experiencia deshonrosa: su cautiverio. Por medio de una estructura de dualidades, la narración autobiográfica coexiste con la reflexión histórica del conflicto bélico, del mismo modo que su objetivo imperialista: "manifestar y dar a entender las causas y fundamentos que se hallan para que esta guerra de Chile sea inacabable y perpetua" (Núñez, Cautiverio, 73) convive con la caracterización positiva de los araucanos.

Ante esta dicotomía, los primeros críticos aislaron en su estudio -incluso en sus ediciones- las partes más narrativas de las más digresivas sin tener en cuenta que la heterogeneidad discursiva de esta crónica es la base de la retórica de su escritura. A este rasgo se refirió Walter Mignolo como el carácter "mixto" del texto, pues encontró en él marcas de "la literatura, la historia y la oratoria" (359). De hecho, hasta la crítica más reciente no se acepta el propósito que el propio Francisco Núñez de Pineda y Bascuñán marca en su texto, sino que, por haber dado prioridad en su análisis al discurso narrativo y autobiográfico, se defendía como objetivo textual la defensa del araucano. Aun así, nos parece muy interesante que las voces de estos naturales estén presentes, siempre mediadas por el autor, para contribuir al fin de su escritura y, por ello, vamos a rastrearlas dentro de la pluralidad discursiva del texto.

Para cumplir este objetivo, tendremos en cuenta todas las partes de la crónica, es decir, los cinco discursos centrales, la Suma (los resúmenes de estos), el Epílogo de un tratado político que se cree perdido y la Descripción manifestativa de las calidades de la tierra del Reino de Chile, de su costa y puertos, sucinta y breve (ed.1984). 
MEMORIA INDÍGENA: ORALIDAD Y ESCRITURA

En el siglo XVII, los españoles consideraban a los araucanos un grupo prehispánico que ofrecía una férrea resistencia a la conquista territorial española. Debido al establecimiento del conflicto bélico alrededor de unas fronteras móviles, los bandos mantuvieron contacto e intercambiaron mercancías, prisioneros y comunicación. Los indígenas constituían para ellos un colectivo de lo que Walter Ong denomina "oralidad primaria", es decir, oral y sin conocimiento de la escritura o de la impresión (20), por lo que el intercambio de información que los colonizadores realizaron con ellos se produjo siempre por medio de la palabra hablada.

Debido a la dilatada guerra y a los abundantes intercambios (indios amigos, cautivos, desertores, etc.), no era descabellado encontrarse a individuos conocedores del habla del enemigo a ambos lados de la frontera. De hecho, Núñez de Pineda y Bascuñán entiende y habla mapudungun, y deja constancia de que algunos de los caciques indígenas con los que se topa durante su cautiverio pueden comunicarse en castellano. Sin embargo, ¿el autor tiene acceso al imaginario araucano por hablar su lengua?

El cronista experimenta las interferencias que se dan entre el sistema de comunicación oral de los araucanos y el suyo, pero las gestiona con la confianza de los usuarios letrados y que se debe a que la escritura les permite tener una actitud pasiva frente al paso del tiempo, pues la permanencia de las informaciones es intrínseca a ella (Ong, 82). Sin embargo, no parece ser consciente de que la memoria en ambos sistemas de comunicación no se construyen del mismo modo aunque ansíen la perdurabilidad del pensamiento; ni sus imaginarios e identidades, que se erigen a partir de ella, tampoco.

Con este panorama, la comunicación entre araucanos y colonizadores se presenta a priori complicada. Sin embargo, el autor criollo no solo interactúa con sus reconocidos "enemigos" (Núñez, Cautiverio, 248) en los espacios marcados por el conflicto, sino que voluntariamente registra sus voces en la crónica. Esta decisión dificulta su labor como cronista, pues se aleja de los discursos oficiales que no tenían en cuenta otras versiones de lo acontecido y, sobre todo, se enfrenta a su mayor desafío como autor: el registro de la oralidad en un texto escrito casi 40 años después de los hechos que relata.

En este estudio defendemos que, a pesar del inconveniente que le pueda suponer, la voz del indígena está presente como uno de los elementos de la estrategia retórica del texto porque le sirve para acreditar la veracidad de su historia a partir de una experiencia legitimadora y, en especial, en dos sentidos. Por un lado, testifica el padecimiento que el soldado ha sufrido dando servicio a la Corona, probanza de méritos para que sus peticiones sean concedidas en justo pago y, por otro lado, señala la facilidad con la que los indígenas asimilan la doctrina cristiana.

Por ello, estas voces están integradas en el conjunto de experiencias (también anteriores y posteriores al cautiverio) tras las que el autor reflexiona y presenta al lector su parecer. De las vivencias se extrae lo que, en sus palabras, "habremos menester p[a]ra la principal proposición de este libro" (243), por lo que suponemos que la 
información silenciada -se advierta o no al lector- no contribuye al fin de la crónica y la que se cuenta, cumple una función textual. La voz indígena y su memoria son pues instrumentos que sirven al objetivo del autor y a la retórica del pasado como estructura. La memoria, que Cicerón consideraba una de las cinco artes de la retórica (Yates, 14), es central en la pluralidad discursiva del soldado criollo aunque, a diferencia de las crónicas mestizas, el registro del pasado indígena no persigue en este texto su reivindicación. Sin embargo, su mera presencia amplía -la mayor parte de las veces de manera involuntaria- el punto de vista del yo autor/protagonista.

Núñez de Pineda y Bascuñán nos dice que fue instruido antes de sufrir cautiverio varias veces por su padre, el afamado maestre de campo sevillano Álvaro Núñez, "en el conocimiento de estos bárbaros" (262). Inmerso ya en la experiencia, la interacción con los caciques y la observación de sus hábitos y relaciones en comunidad le permite tomar el primer registro directo de los araucanos por medio de la observación. Después de haber sido liberado, contrasta los datos obtenidos con otras versiones y se apoya en documentos probatorios como imágenes, cartas, etcétera, para ofrecer al lector de la crónica una historia los más fiel posible a la realidad.

Durante el cautiverio, la voz del indígena puede ser una fuente "farisea" (290) o veraz, por estar o no ajustada a la racionalidad y a la experiencia ("que a no haberme dicho que fuisteis testigo de la acción, no sé si diera crédito al caso" [561]). Esta fractura entre la credibilidad de los araucanos se produce desde su captura y en el posterior consejo de guerra (Discurso 1). El autor, que iba "haciendo memoria de aflicción y de pena" (252) en la escritura, cede paulatinamente su voz al diálogo que mantiene con Lientur, un indígena que se apiada de él y que se enfrenta al resto de caciques para que conserve la vida. En un primer momento, asume la intervención del cacique en estilo indirecto: "preguntarme si era hijo de Álvaro" (271), pero luego cita con literalidad sus palabras, haciendo hincapié en la rigurosidad con la que reproduce su voz: "repito lo que formalmente fue diciendo" (271). Esta fórmula aspira a la veracidad de los hechos mediante la reproducción literal de la experiencia.

Más adelante, sucede el consejo de guerra que el autor juzga como un "bárbaro y mal rito" (298) porque se mata a otro prisionero y se reparte su corazón a los miembros de la comunidad para que se lo coman. Durante la ceremonia, la supervivencia de Núñez de Pineda y Bascuñán se debatirá entre dos facciones: la de los caciques que desean su muerte por ser hijo de un soldado español y la de los que consideran que su genealogía no invita más que a agasajarlo hasta el momento de su rescate e intercambio. En la escritura, el autor justifica la primera de las actitudes, la que es contraria a su suerte, con la presencia del demonio entre los comensales y la segunda, más benigna y deseable, con la prevalencia de la razón.

Será, además, en este consejo donde Maulicán resuelve que, cumpliendo el encargo que le hizo Lientur, conduzca al prisionero a su distrito con la condición de que lo traiga de vuelta a los quince días. Como, pasado el tiempo estipulado, Maulicán decide no entregarlo, Núñez de Pineda y Bascuñán experimenta su cautiverio lejos de la 
frontera y de los indígenas más belicosos. Así tiene la oportunidad de convivir con indígenas filohispánicos, a partir de cuyas voces experimenta un encuentro parcial con la otredad. Por este motivo, la reconstrucción en la escritura del discurso indígena será una alocución artificial al haberse configurado desde la racionalidad que les atribuye y por su intermediación como distribuidor de la palabra.

\section{EL REGISTRO LETRADO DE LA MEMORIA INDÍGENA}

Núñez de Pineda y Bascuñán tiene que hacerse cargo de una amplia polifonía de voces, pero no parece tener más impedimento que la comunicación de ciertos términos nativos. No se percibe la heteroglosia en la que los actantes se ven obligados a convivir en la crónica, ni tan siquiera a la hora de representar la oralidad indígena. El autor, ajeno al conflicto, plantea la crónica en castellano, una decisión acorde con la recepción que se espera de ella en la Corte española, y transcribe algunas palabras del mapudungun para después traducirlas por medio de una equivalencia funcional por medio de las siguiente fórmulas: "que es...", "es la que llaman..." (291), "que llamamos..."(351).

La muestra lingüística de palabras como canoa, huinca, toqui... es pura arbitrariedad exótica cuya presencia simplemente ratifica la experiencia comunicativa. Sin embargo, los casos en los que se da un contrasentido al término que se expone, evidencian un desacuerdo con el significante al que hace referencia más que al signo que lo remite. Es el caso del término hu[y]elpurún, que se introduce como "la suerte que es este baile" (381) y que, una vez observado su funcionamiento, se corrige en la misma página por "entretenimiento deshonesto". Termina por fijarse con una traducción cultural y no solo lingüística: "que quiere decir baile deshonesto" (426), en la que se evidencia la manipulación ideológica de los hábitos y de la ritualidad de la comunidad y, por tal razón, de su memoria cultural. El cronista no duda al clasificar lo que experimenta, pues se siente prestigiado por la escritura para relatar los sucesivos encuentros.

Ni siquiera la reproducción de las canciones presenta un problema en la crónica. El ejemplo paradigmático es el que se produce en el discurso 4, capítulo 12, en el que se transcribe del mapudungún una tonada que el autor considera un "romance" (892) y en la que dice reconocer versos medidos "a imitación y semejanza de nuestras líricas endechas" (892). Para dejar constancia de esta curiosidad separa gráficamente las sílabas de cada verso ("Ab-cu-du-am-in-e-ma" [892]), luego los transcribe para los lenguaraces criollos sin métrica ("Ab cuduam in, ema" [893]) y, al final, los traduce al castellano ("Muy lastimado tengo" [893]).

Por otra parte, los diálogos similares al que el soldado mantiene con el cacique Lientur al comienzo del cautiverio se reproducen totalmente en castellano, salvo alguno de los apuntes lingüísticos ya mencionados. No hay marca en el texto que constate que se trata de una traducción de una lengua originaria, ni está el subtexto de un pensamiento indígena -reconocible en la crónica mestiza- cuando estos hablan (por escrito) directa o indirectamente. En cambio, sí hay en sus voces una manipulación 
mediante la elipsis (prolepsis y analepsis) y de los silencios. Por ello, o bien se manifiesta en el texto una homogeneización voluntaria de las voces que participan, y que así organizan ideológicamente lo narrado, o bien persiste en el soldado cautivo una actitud etnocéntrica que lo ciega frente a la diferencia.

Con el objetivo de clarificar en lo posible su naturaleza, revisaremos cómo se formula el contenido de los diálogos que el soldado experimenta con los indígenas, pues el abuso de la técnica dialógica que hemos referido más arriba -sobre todo en los tres primeros discursos- es notable. Los que siguen al que mantiene con Lientur, rememoran la valentía de su padre, su propia fidelidad a Maulicán, ahondan en algunas costumbres de los naturales, plantean una crítica a algunas acciones de los españoles en la guerra $\mathrm{y}$, especialmente, revelan la otra versión de dos hechos cruciales en la historiografia de la Colonia: la muerte sonada de tres jesuitas en 1612 y la de Pedro de Valdivia en 1553.

La muerte de los jesuitas se rememora en la conversación que mantiene Núñez de Pineda y Bascuñán con el ejecutor de los hechos, Ancanamón, en el discurso 2, capítulos 10 y 11 . El diálogo, que comienza en estilo indirecto, se da en el interior de la casa del cacique mientras 4.000 indios celebran en el exterior una fiesta en su honor. El clima es apacible para conversar y el soldado le pregunta acerca de la muerte de los religiosos, pero Ancanamón sortea la pregunta con alabanzas a su padre Álvaro ("no habían conocido persona de tanta opinión ni que fuese tan temido de ellos" [Núñez: 414]). Tras estos preliminares, el autor deja constancia de que el cacique le vuelve a preguntar "qué es lo que decían de él entre nosotros, si tenía opinión de soldado y de valiente" (415), a lo que responde asegurándole que no había otro nombre más conocido entre los españoles "pues hasta los niños y mujeres tenían en la memoria el de Ancanamón" (415). El cacique, halagado, pierde el miedo a contar su versión de lo sucedido aun sabiendo que las glosas oficiales lo culpan del hecho.

El objetivo del soldado al interesarse por este suceso es "tener sertidumbre de lo que informes varios han puesto dudoso" (415); en resumen, contrastar la información de los documentos oficiales con la voz del cacique, contenedora de la memoria que ha sido transmitida a la comunidad. Interpelado y animado por el soldado ("Proseguid con vuestra historia -dije a mi amigo..." [418]), Ancanamón cuenta que el padre Luis de Valdivia ideó un tratado de paz con los araucanos que consistía en la no agresión de las partes. Para oficializar este plan se permitió el paso a territorio indígena de un embajador llamado Meneses y de su intérprete. El español traicionó las paces llevándose a tres de sus mujeres al fuerte de Paicaví y no quiso devolverlas cuando fueron a reclamarlas. Obligado a defender su honor ante sus suegros, el cacique prometió que se vengaría con los siguientes españoles que cruzaran la frontera. La llegada de los tres jesuitas, a quienes dio muerte, favoreció la venganza pero puso punto final a las paces.

Cuando el cacique termina su intervención, Núñez de Pineda y Bascuñán pondera las razones que le ha dado y las contrasta con los documentos -"la letra de lo 
sucedido" (420)- a los que tiene acceso "después de conseguida [su] libertad" (420). Ante todo concluye que Ancanamón no actuó "en odio de la fe" y que se "exageran la muerte de los padres de la Compañía de Jesús, acción de un corazón bárbaro y lastimado" (422).

El apoyo que da a la versión del cacique no certifica la realidad sino lo que la memoria indígena de este hecho conserva que, a su vez, está intermediada por la escritura. Como ya hemos visto, el principio de racionalidad en los buenos araucanos viene formulado intencionadamente por el propio autor desde el primer encuentro que tiene con ellos. Por eso, es curioso que se nos presente a Ancanamón diciendo: "mirad ahora si tuve sobrada razón o no, después de recibidos los agravios que os he referido" (420, el destacado es mío), de la misma forma que se introducen palabras en mapudungun con la misma técnica que el soldado aplica en sus parlamentos. En este sentido, es reseñable que unos capítulos antes, Núñez de Pineda y Bascuñán destaque que a los indígenas les falta la unión que da un gobierno y que el cacique subraye en sus argumentos lo que podrían haber sido las palabras del soldado criollo:

[...] que si había algunos que supiesen distinguir lo bueno de lo ma[1]o y considerar que también hay malos españoles como buenos, y que los que no son ajustados a la razón tienen gobernador y cabeza superior que los castiga, como yo y otros lo entendemos así, los más y el común jusgarían (419, el destacado es mío).

Más adelante, se vuelve a referir el hecho en la Suma de la crónica. En ella, dice referirse "lo esencial y más conveniente para la demostración de mis intentos y verificación de mis escritos", por lo que entendemos que este relato cumple también una función textual en los resúmenes a los que, acorde con su objetivo, le sigue una reflexión de los hechos (Núñez, Cautiverio, 73). Recurre de nuevo a la reproducción de la voz del cacique en estilo directo, pero con sorpresa descubrimos que las citas no reproducen las mismas palabras. La figura de Luis de Valdivia tiene mayor presencia que en los discursos -queda como "el que trataba de saludables medios de paz, aunque por malos intérpretes" (92) - y las autoridades que la voz del indígena le evoca han variado. En el cuerpo central de la crónica, las citas se le atribuyen al obispo Villarroel, a San Crisóstomo, a San Ambrosio y provienen de los libros bíblicos del Éxodo o el de los Reyes; y en el resumen, son Cicerón, el profeta Natán, el rey David o el libro del Eclesiástico los que legitiman sus divagaciones. Es obvio que estas fuentes son parte de la retórica de la escritura y que no provienen de la experiencia de la conversación con Ancanamón, como nos intenta hacer creer. Sin embargo, el apoyo que estas autoridades dan al contenido de la memoria local una vez que ha pasado a ser escritura-frente a la hegemónica, equilibra la trascendencia que tenía y permite que el soldado, con inocencia, las contraponga como dos manifestaciones de una misma categoría de pensamiento.

La rememoración de la muerte de los jesuitas es pues un caso único en la crónica porque, al mismo tiempo que critica el modo en el que la Corona conduce la guerra, persiste en su alegato a favor de la guerra defensiva y en la docilidad de los araucanos conveniente para evangelizarlos. Solo el episodio en el que se narra la muerte de Pedro 
de Valdivia se le asemeja porque recupera la memoria indígena de un hecho pasado gracias a la escritura. Sin embargo, su desarrollo textual presenta más problemas al autor porque el recuerdo se desempolva a partir de la rememoración que hacen los caciques de los "primeros conquistadores" y tiene que lidiar con la construcción de la memoria indígena y su trasmisión.

\section{CONSERVACIÓN Y TRANSMISIÓN DE LA MEMORIA INDÍGENA}

Núñez de Pineda y Bascuñán refiere la muerte de Valdivia en el discurso 3, extendiendo el relato entre los capítulos 10 y 20. Cuenta el soldado que en casa del cacique Naucopillán estaban "haciendo memoria de los pasados conquistadores" (558), cuyos recuerdos no eran otros que el maltrato al que fueron sometidos aquellos años. Ante la incredulidad del soldado y las ganas de conocer más, uno de los caciques presentes señala al anciano Aremchéu como el cacique más autorizado entre todos para relatar esos hechos, pues "no hay otro más antiguo" (559). La decisión que toma el grupo de viejos caciques expone dos aspectos de la memoria araucana: por un lado, que los recuerdos se crean a partir de la experiencia ("lo que sé deciros [...] porque mi amo nos hacía buen tratamiento" [559]) y, por otro, que estos recuerdos se transmiten entre generaciones (dice Aremchéu: "solo las noticias de mis padres tengo presentes" [559]).

Aunque los ancianos en la crónica siempre sean los portadores de la memoria colectiva, Núñez no presta especial atención al proceso de transmisión y sí a que los recuerdos que le cuenten estén basados en la experiencia. De hecho, se preocupa en dejar constancia de que uno de los caciques, que fue entonces indio tributario, replicó a uno de los recuerdos de Aremchéu, advirtiendo cómo la memoria cambia según los hechos que cada individuo sufra:

[... ] vos solo podéis hablar de esa suerte de vuestro amo y los de su encomienda, porque tenían diferente tratamiento que nosotros, y los más del reino no podemos decir eso, porque no nos dejaban sosegar en nuestras casas, ni gozar de nuestros hijos y mujeres (559).

El criterio de autoridad etnocéntrico del soldado -en el que la experiencia es sinónimo de veracidad- se ha entrometido en el proceso de construcción de la memoria indígena y sobresale sobre todos los elementos que participan en ella. Así se explica que Núñez de Pineda y Bascuñán escoja a los caciques que más le interesan porque entiende que los individuos, a partir de sus experiencias acumuladas, son los creadores de su memoria y no solo sus conductores. Parece no comprender que, a pesar de las diferencias entre las memorias individuales de los caciques, la unión de todas ellas es la que configura la memoria colectiva que los unifica como grupo (Halbawachs, 10) y de la que se alimenta su crónica, aun en la disparidad de versiones y en el continuo replanteamiento que sufre la memoria en la oralidad.

Por ello, espera a regresar a casa de Tureopillán, el primo de Naucopillán, para preguntar a un cacique más experimentado respecto de la muerte de Valdivia. En los 
capítulos anteriores ha frenado los recuerdos sobre los "primeros conquistadores" y cuando retoma la narración, ha pasado bastante tiempo intradiegético, por lo que el cambio de escenario es también muy conveniente. Según el soldado, Tureopillán es un indio ajustado a la razón y a la verdad, pero era muy joven cuando se produjo la muerte de Pedro de Valdivia, por lo que su relato se construye a partir de la "opinión" de otros (Núñez, Cautiverio, 593). Sin embargo, el soldado da credibilidad a su versión porque se asegura de que ningún otro tiene "tan presentes" el suceso, es decir, su memoria cumple con lo que se espera de ella, traer al presente los hechos pasados (592). Núñez de Pineda y Bascuñán acepta pues que murió a garrote y con oro en la boca, y que hay algunas versiones que "dicen que" fue Lautaro, su criado, quien eligió la forma en la que se ejecutó su muerte (593).

La oralidad de la conversación se reconstruye en la escritura como el episodio de la muerte de los jesuitas: por medio de citas directas e indirectas, con el aliento del autor a las palabras del cacique ("Prosegu[i]d amigo" [593]/"Desís muy bien" [594]), pero con una diferencia: este episodio no aparecerá en la Suma vinculado a la conversación de los ancianos del capítulo 3 sino a la del resumen del capítulo $4 \mathrm{y}$, además, brevemente. En el capítulo 3, la elipsis de este hecho es voluntaria y se explica así:

$[\ldots]$ con que tuvo ocasión de insinuarme la desenvoltura y ningún recato con que vivían nuestros primeros conquistadores; que, porque en el original deste breve epílogo van bien manifiestas sus desmedidas y mal atentas acciones, no refiero más de que respondí al cacique que por semejantes disolusiones como las que me había referido habían sido severamente castigados de la mano de Dios (104).

Y en el capítulo 4 se refiere la muerte de Valdivia con esta escueta nota:

[...] si no es que permite la Divina Justicia que perescan desastradamente a manos de sus propios vasallos nuevamente reducidos, como lo experimentaron los primeros gobernadores de Chile, don Pedro de Valdivia y don Marín García Óñez de Loyola, con muertes raras y particularmente desastres, como más latamente se refiere en el libro de mis discursos (117).

En síntesis, la Suma expone la venganza terrenal de los indígenas con brevedad y como un acto de la Divina Providencia que, a la vez que supedita a los araucanos a ser instrumentos de su plan divino quitándoles el mérito de la acción, manifiesta el patrocinio divino de la conquista. El relato se adapta, por tanto, a los intereses del cronista que no permite que los recuerdos araucanos de los primeros conquistadores desvíen la atención de la crítica a la conquista actual.

Sin embargo, recurre a ellos cuando le resultan útiles para explicar alguna de las causas en la dilación de la guerra, por ejemplo, la desatención que muestran los presentes conquistadores a los consejos de los soldados experimentados. Para construir esta crítica, atiende al proceso de transmisión de la memoria araucana -marginado en el relato de la muerte de Valdivia- aunque se preocupa de adscribirlo a una experiencia: la sorpresa que despierta entre los indígenas al rechazar a la hija del cacique Quilalebo 
como regalo. Esta vivencia le permite darse cuenta de lo "impresas" que tienen "en la memoria las acciones de nuestros antepasados" (663), pues, al parecer, era costumbre de los antiguos conquistadores aceptarlos con gusto.

La manera en la que se conservan este tipo de recuerdos, y no otros, se explica al lector por el principio de supervivencia de los araucanos que, por tradición, los alienta a comunicar los unos a los otros selectivamente sus recuerdos. Así se conservan en el pensamiento colectivo aquellos acontecimientos que fueron perjudiciales en el pasado del grupo y se mantienen alerta ante una posible repetición ("tenemos tan en la memoria, que es imposible que la tierra vuelva a sujetarse a los españoles" [696]). Estos recuerdos tienen una correspondencia directa en el imaginario colectivo mediante los proverbios, los consejos, las costumbres, los ritos, etc., fórmulas más o menos complejas que, con su repetición, contribuyen tanto a su permanencia como a su actualización. Quizás Núñez de Pineda y Bascuñán no fuera consciente de las relaciones entre estas manifestaciones y la memoria araucana y, aunque sí lo fuera, no es su objetivo mostrarlas. En cambio, para este estudio, este testimonio más secundario nos permite profundizar en otros ámbitos de su proceso.

\section{LAMEMORIA INDÍGENA Y LOS RITOS}

La memoria colectiva de los araucanos se adapta a la estructura de los indígenas como grupos patriarcales y a las relaciones estrechas que los caciques de distintos distritos mantienen en la toma de decisiones que requieren una unión mayor: frente a los colonizadores (parlamentos o juntas de guerra), en la distribución de las tareas agrícolas o en la celebración de acontecimientos. A pesar de que el autor atribuya a los caciques iniciativas individuales -también puntualiza, como hemos visto, la independencia de sus memorias-, la vitalidad de la comunidad obliga a este vínculo entre familias por medio de los recursos memorísticos, asentados principalmente en la ritualidad.

Los ritos no son solo una acumulación de recuerdos individuales sino "modelos, ejemplos y enseñanza" (Halbwachs, 181) que, como la memoria, se comunican por otros mecanismos de la oralidad, el lenguaje no verbal, la música, la escenografia (Florescano, 15) y, sobre todo, la repetición. Núñez de Pineda y Bascuñán refiere muchos de estos hábitos y celebraciones poseído por una mirada curiosa y exótica más que utilitaria, pues, en principio, no contribuyen al fin declarado del texto. Por un lado, observa cómo se desenvuelven los indígenas en cualquiera de los actos y concluye, en un ejercicio elemental de asociación con su imaginario, que "son muy parecidos a la de los antiguos" (Núñez, Cautiverio, 330); especificará en la Suma, a los antiguos hebreos. Por otro lado, cuando participa en ellos -por lo general, obligado por las circunstanciasse muestra contrariado porque atentan contra su moral religiosa. No solo define al hu[y] elpurún como un "entretenimiento deshonesto" (381), sino que el baño diario expone con inmoralidad el cuerpo de las mujeres (317), los machi o curanderos actúan "por arte del demonio" (362), la costumbre de echarse sobre sus muertos es 
"lamentosa" (492), las mujeres son "impertinentes" cuando se emborrachan (860), etc.

Solo ciertas costumbres de estos naturales son "memorables" (735) -dignas de ser recordadas- o son "buenas costumbres" (736): en las que intervienen los niños (el juego de la pelota [321]) o en las que muestran su compromiso en la guerra (la abstención sexual antes de la batalla [D.: 4 c.: 19). Lo que sorprende al autor sobre este punto es que "unos infieles bárbaros, sin discursivo natural" (737) hayan identificado los vicios que atentan contra el buen desarrollo del conflicto en La Araucanía y los conquistadores aún no. No será casual tampoco que sean los más jóvenes a quienes él instruya en la religión católica, ni a los que les reserve las voces de la disidencia, porque en ellos se marcan menos los rasgos de la memoria colectiva, ya que aún están siendo instruidos por los ancianos del grupo.

Estos ancianos son siempre hombres que adscriben su acto de oratoria a un espacio y se dirigen al grupo con un mensaje que potencia la identidad, que vincula a los miembros entre sí. Por ejemplo, la junta de guerra se celebra en el lepum, al que Núñez de Pineda y Bascuñán define como "un sitio distante y apartado del común concurso media legua o una, poco más o menos" (373), y que luego traducirá: “-como si dijiese 'en el senado'-" (373), una asociación que prestigia la organización indígena al compararla con otra de una sociedad tan célebre como la romana. El lepum favorece además lo que el soldado considera un "razonamiento retórico con estilo, sólido, masivo y grave" (909), esto es, unos procedimientos que aseguran la efectividad del discurso, legitimando la transmisión de los ancianos como si fueran senadores latinos.

A partir de esta afirmación, podemos deducir que o bien el autor otorga a los bárbaros cierta gobernabilidad como la que organizaba la vida europea, en contradicción con lo que él mismo expresa en otros capítulos de su crónica, o bien persigue ennoblecer el relato de su experiencia, realzando un cautiverio que por pacífico tiene pocas historias reseñables. Sea cual sea su motivación, la estructura del lepum es un método tan efectivo que el soldado lo incluye más tarde en su alocución con el fin de persuadirlos ("-les dije, hablando conforme a su costumbre" [837]). Esta lógica le lleva a asumir también la mnemotecnia, una técnica memorística que estudiaremos en la siguiente y última sección de este estudio.

\section{LAMEMORIA INDÍGENAY LAMNEMOTECNIA}

Más arriba dijimos que, durante la junta de guerra posterior a la captura de Núñez de Pineda y Bascuñán, se mata a un soldado y se reparte ritualmente su corazón entre los asistentes. Antes de ejecutar el acto, el cacique P[B]utapichún - al que el más anciano cede $\mathrm{su}$ voz porque se sabe "poco retórico" (291)- tortura al prisionero con un juego memorístico en el que debe asociar cada uno de los palillos que le ofrece con un capitán del ejército chileno. P[B]utapichún, que actúa como "maestro de ceremonias" (297), le pide al soldado que memorice la información que queda registrada en los doce palillos conseguidos y que la repita frente al parlamento, tirándolos a un hoyo para simbólicamente enterrar a estos capitanes. Con mucho esfuerzo, el soldado dará solo un par de nombres de los adscritos, pues no tendrá tiempo de reproducir todos ellos antes de 
que le golpeen en la cabeza y muera.

Esta "ceremonia" (292) nos interesa especialmente porque demuestra que los araucanos no solo practicaban la rememoración sino también la mnemotecnia, esto es, el procedimiento de asociación mental para facilitar el recuerdo de algo. Dicha alocución ha sido teorizada en tratados filosóficos, políticos y religiosos hasta el Barroco, lo que evidencia su utilidad y el poder que su control ofrece en cada época histórica. Como optamos por no hablar de historia indígena, se nos hace complicado sistematizar la mnemotecnia araucana en relación con la occidental, más cuando el autor evita expresar las diferencias entre ambas y acentúa los elementos homogeneizadores. Sin embargo, el hecho de que en dos grupos humanos con estructuras de pensamiento tan dispares se dé un mismo proceso mental muestra que, como se asegura en Ad Herennium, el hombre posee dos tipos de memoria complementarias: la natural y la artificial (Yates, 17). Mientras que la natural es la actividad innata del pensar, la artificial aboga por la conservación y transmisión de ese pensamiento por medio de diversas técnicas que, aunque se hayan sofisticado con las exigencias de los tiempos, tienen su base en la relación entre imágenes y lugares de Quintiliano (15).

El espacio concreto donde se reúnen los participantes en la ceremonia descrita es el "palenque", un lugar al que los araucanos asocian usos rituales religiosos y de guerra (González y Rosati, 79). La carga simbólica del palenque como locus interfiere en la práctica de los palillos que, a su vez, son contenedores -como debieran de ser las imágenes en la teoría clásica de la memoria- de aquello que se quiere conservar en el pensamiento, en este caso, de los capitanes enemigos. Por el asiento y la eficacia de esta práctica entre los araucanos, Núñez de Pineda y Bascuñán decide apoyarse en ella durante el proceso de evangelización que inicia con los indios más jóvenes, en el que la memoria será transmisora de recuerdos, pero también de ideología.

En la divulgación de la fe, Núñez de Pineda y Bascuñán sigue el modelo evangelizador de las reducciones americanas de la Compañía de Jesús. Por ello, no debemos pasar por alto que iniciativas como traducir las oraciones a la lengua nativa $o$ explicar los dogmas a partir de asociaciones son actitudes que los jesuitas llevaron a cabo para ofrecer unas misiones en profundidad. Por su parte, en su afán de demostrar que los araucanos están naturalmente predispuestos al catolicismo, Núñez de Pineda y Bascuñán utiliza a los niños como objetivo de su predicación y deja que sean ellos los que lo requieran como apóstol.

La primera vez que se plantea en la crónica este escenario tan favorable es en el discurso 2, capítulo 3, cuando el soldado se dispone a dormir con el anciano Llancaréu y sus nietos (padre e hijos de Maulicán). Relata que se santiguó "despacio" (375) para buscar la protección de Dios y que el cacique le preguntó el porqué de aquellas "señales" (375). Cuando supo que las hacía para ahuyentar al demonio quiso que se las explicara a sus nietos, a lo que respondió con buena voluntad que además les enseñaría a rezar "para que invoquen el nombre de Dios y le conozcan" (375). Además, añade que se los mostrará en su lengua porque "de haber oído doctrinar a nuestros domésticos indios 
algunos ratos, tenía las tres oraciones, hasta el credo, en la memoria" (376).

En este episodio se evoca la doctrina religiosa mediante las oraciones y algunos gestos o ritos, como contenedores de la memoria católica que son. Más adelante, cuando en el capítulo 6 quiere fijar en cada uno de ellos el Padre Nuestro, les insta a la repetición hasta que lo memorizan sin dificultad. Sin embargo, cuando les explica los dogmas de la fe opta por apoyarse en las asociaciones por similitud para facilitarles, lo que Aristóteles llamó, la "recordación" (cit. en Yates, 50), es decir, la recuperación de un recuerdo entre todos los que ocupan el imaginario de cada ser humano o colectividad. No entra a discutir con sus pupilos, como sí hace con el lector, que las traducciones culturales o lingüísticas no sean exactas y que hay disimilitudes, por ejemplo, entre el pecado católico y el de los araucanos o huerilcán.

Por otro lado, la crónica nos enseña que los araucanos son constantes en la repetición de las oraciones ("repetímosle tres o cuatro veces" [Núñez, Cautiverio, 450]) y que Núñez de Pineda y Bascuñán comprueba que las tienen "en la memoria" (545). Sin embargo, hasta que no entienden gracias a las traducciones lo que dicen, no pueden incorporarlas a su imaginario sin conflictos e iniciar algún tipo de proceso de transmisión como los que hemos descrito en este trabajo. Llegan entonces a introducirlas en sus cantos rituales e incluso a criticar a los apóstatas españoles, una actitud que sería consecuencia de la "asimilación" (Zamora, 137) derivada de la apropiación de la voz araucana por parte del soldado.

La memoria araucana, flexible y en continua permeabilidad, se disputa la permanencia de sus rasgos frente a los que la memoria occidental desea incorporar, basados en la escritura y en un sistema mnemotécnico de imaginería que desde la Edad Media es muy sofisticado. Núñez de Pineda y Bascuñán no puede, como hombre de su tiempo que es, estar al margen de la complejidad de la transmisión de la doctrina católica. Prueba de ello son las complejas autoridades -los padres de la Iglesia- que trae a colación para mostrarse ante el lector (y no ante los araucanos) como un gran conocedor de los dogmas religiosos. Al mismo tiempo sorprende que sus recursos para interceder en la memoria araucana sean tan clásicos, cuando su religiosidad es barroca, es decir, basada en un potente culto a las imágenes y a los misterios que encriptan.

Tras el catequismo mediante la memoria, Núñez de Pineda y Bascuñán cree que la evangelización ha sido un éxito porque incorpora la palabra de Dios, la "memoria artificial cristianizada" como la entiende San Agustín (cit. en Yates, 66), a la oralidad contenedora de la memoria de los indígenas. En apariencia no se da un conflicto entre el catolicismo y el imaginario araucano, pues no se suplanta ningún sustrato religioso anterior, sino que se aprovechan los espacios vacíos de la memoria colectiva y se rellenan con la teología católica. Ante la manipulación de la voz de los naturales que viene realizando el autor, nos preguntamos si esas partes del imaginario que la evangelización completa no son sino los espacios que ocupaban recuerdos anteriores que el autor silencia -porque no ha sabido reconocerlos en ritos, porque no ha querido referirlos o porque ha rechazado su credibilidad (como los de los machi)-.

Núñez de Pineda y Bascuñán no quiere dejar dudas al respecto y relata con 
entusiasmo los episodios epifánicos en los que los niños, tras haber aprendido alguna de las oraciones o dogmas, sueñan con ellos ratificando así su adhesión en su pensamiento. El sueño se explica a partir de la concepción de Cicerón, es decir, como "pensamientos o palabras continuadas en la memoria en el dizcurso del día" (466), cuya teoría aplica con libertad para justificar por ejemplo las ganas de uno de los jóvenes de bautizarse (467). El hecho de que se haya soñado con las enseñanzas religiosas significa que se han asentado en la memoria y que el método, aplicado sobre los principios orales de la memoria indígena, es útil.

Sin embargo, el soldado no parece atribuir el éxito de la evangelización a la eficacia de la mnemotecnia, sino a que el contenido que memorizan es congénito a ellos. Un pensamiento que daría pie para suponerles a los araucanos una creencia precristiana -como la que se había atribuido a los Incas- que los convertiría en los destinatarios naturales de la evangelización. De no ser así, la docilidad innata que les atribuye ante los dogmas de la fe no se explica, ni el proceso evangelizador hubiera alcanzado la profundidad que el soldado presume que ha introducido en ellos. El mensaje contradice, además, la acusación de herejía que en la época se vertía sobre estos indígenas, descargándoles de la mayor parte de la responsabilidad moral en la dilación de la guerra por La Araucanía y señalando como culpables a los conquistadores. Estos son aquellos ministros, virreyes y mandos del ejército español en América que no administraron con justicia el conflicto -ni su carrera como soldado- y contra quienes Núñez de Pineda y Bascuñán utiliza la memoria del enemigo indígena.

Como hemos referido a lo largo de este artículo, esas voces han estado intermediadas en todo momento por el objetivo del cronista aunque también por su imaginario, propio de un criollo fronterizo y cautivo que, a pesar de haber convivido con la alteridad, no las entiende. El tratamiento positivo que se le da a estas voces en la escritura viene tras haber reconocido en ellas rasgos propios del pensamiento occidental, por lo que el autor siente que los propios araucanos apoyan sus preceptos. Por este motivo, cuando sus diferencias parecen irreconciliables, se siente acreditado para supeditar sus voces al fin imperialista de su texto por medio de los procedimientos aculturadores que hemos revisado, como el control de la memoria indígena y sus procesos de conservación y de transmisión.

Universidad Complutense de Madrid* Facultad de Filología Lealas 57, $1^{\circ} \mathrm{B}, 11404$, Jerez de la Frontera-Cádiz (España) slopezbaena@ucm.estumail.es

\section{OBRAS CITADAS}

Florescano, Enrique. La memoria indígena. México: Taurus, 1999.

González Vargas, Carlos y Hugo Rosati Aguerre, "Rescate de una construcción mapuche no conocida", Aisthesis, Revista chilena de investigaciones estéticas 39 (2006): 
72-84. En línea http://dialnet.unirioja.es/servlet/articulo?codigo=2358114 Halbwachs, Maurice. Los marcos sociales de la memoria. Traducido por Manuel Antonio Baeza y Michel Mujica. Barcelona: Anthropos, 2004.

Mignolo, Walter. "Metatexto historiográfico e historiografía indiana", Modern Language Notes 2, (1981): 358-402. En línea: www.jstor.org/stable/2906354

Núñez de Pineda y Bascuñán, Francisco. Cautiverio feliz. Santiago de Chile: RIL, 2001.

_ Francisco. Suma y epilogo de lo más esencial que contiene el libro intitulado Cautiverio feliz, y guerras dilatadas del Reino de Chile. Santiago: Sociedad Chilena de Historia y Geografia y Ediciones Universidad Católica de Chile, 1984.

Ong, Walter J. Oralidad y escritura. Tendencias de la palabra. Trad. Angélica Scherp. México: Fondo de Cultura Económica, 1987.

Triviños, Gilberto. "No os olvidéis de nosotros': Martirio y fineza en el Cautiverio feliz". Acta literaria 25, 2000. En línea: www.scielo.cl/scielo.php?pid=S0717$68482000002500008 \&$ script $=$ sci_arttext

_ La polilla de la guerra en el reino de Chile. Santiago: La Noria, 1994.

Yates, Francis A. El arte de la memoria. Trad. Ignacio G. de Liaño. Madrid: Siruela, 2005. Zamora, Margarita. "América y el arte de la Memoria". Revista de crítica literaria latinoamericana 41 (1995): 135-148. En línea: www.jstor.org/stable/4530800 